\title{
Effect of Divalent Metal Ions on Thermal Evolution and Band Gap Energy of Cadmium Oxide (CdO) Nanocrystallites: Comparetive Study
}

\author{
Chitra Bhukkal $^{1 * \bullet}$ Rachna Ahlawat $^{2} \bullet$ Surender Ahlawat $^{3}$ \\ ${ }^{1}$ Physics Department, Government College, Adampur, Hisar, Haryana-125052, INDIA \\ ${ }^{2}$ Department of Physics, Chaudhary Devi Lal University, Sirsa-125055, INDIA \\ ${ }^{3}$ Department of Economics, Chaudhary Devi Lal University, Sirsa-125055, INDIA \\ *Corresponding Author Email: chitrabhukal@gmail.com
}

Received: 28.8.2021; Revised: 16.9.2021; Accepted: 20.10.2021

CSociety for Himalayan Action Research and Development

\begin{abstract}
In this study, pure and divalent metal ions doped cadmium oxide samples are synthesized by cost effective co-precipitation method at the nanoscale dimensions. Here, we have represented a comprehensive study which conclude that how structural and optical behavior of undoped cadmium oxide has been modified with single doping of $\mathrm{Cu}, \mathrm{Mn}$ and their co-doping $(\mathrm{Cu}-\mathrm{Mn})$ also. The prepared nanopowder is being investigated using different complementary techniques like TG-DTA and UV-Vis spectroscopy to explore their bandgap energy and thermal behavior. A strong and broad optical absorption band is obtained at 262, 250, (312 and 475), (250-350) nm for respectively samples. The optical band gap values are calculated using Tauc's plot as 4.45, 3.86, 2.39 and 2.44 eV for undoped $\mathrm{CdO}, \mathrm{Cu}$ doped $\mathrm{CdO}, \mathrm{Mn}$ doped $\mathrm{CdO}$ and $\mathrm{Cu}-\mathrm{Mn}$ co-doped $\mathrm{CdO}$ respectively. UV-Vis spectra revealed that the prepared samples are having high absorbance and extended sufficiently into visible region. Therefore, it is suggested that the co-doping efficiently alter the band gap of the $\mathrm{CdO}$ and make it suitable for optoelectronics and other applications like gas sensing, photo catalyst etc.
\end{abstract}

Keywords: Band gap Energy, co-doping, $\mathrm{Cu}, \mathrm{Cu}-\mathrm{Mn}$ doped $\mathrm{CdO}, \mathrm{Mn}$, TG-DTA analysis

\section{Introduction}

Nanocrystals of II-VI compound semiconductors are widely attracted due to their enhanced structural and optical characteristics in the field of nanoscience and nanotechnology. From II-VI series of elements, Cadmium Oxide $(\mathrm{CdO})$ is found to be the most versatile transparent conducting oxide (Rajput et al., 2017). Pure cadmium oxide generally has its place to the set of TCOs (transparent conducting oxides) holds n-type of conductivity $\left(10^{2}-10^{4} \mathrm{~S} / \mathrm{cm}\right)$, possesses high transparency in the NIR region and narrow forbidden gap (Rajput et al., 2017). Recently, doped $\mathrm{CdO}$ are also investigated due to its large applicability in flat display devices, photonic diodes and thin film electroluminescence (Mohanraj et al., 2018, Purohit et al.,2017). The process of doping would modify its chemical and physical properties up to large extent. In literature, many fabrication processes are reported by researchers for undoped and doped $\mathrm{CdO}$ nanomaterials. Likewise, Gupta et. al have 
reported thin films of $\mathrm{CdO}$ doped with tin and investigated effect of concentration and growth temperature (Gupta et al.,2008). Ziabani et. al have reported the $\mathrm{Al}$ doped $\mathrm{CdO}$ film synthesized with dip coating sol-gel rout. They have investigated the relationship of surface morphology and optoelectronic properties (Ziabari et al., 2012). Siva Kumar et. al have prepared undoped and Silver doped $\mathrm{CdO}$ nanoparticles by the wet chemical procedure (Sivakumar et al., 2015). Also, Usha Rani et. al were represented $\mathrm{Mg}$ doped $\mathrm{CdO}$ and elaborated the physical and optoelectronic behavior (Usha Rani et. al). From these studies, it came into known that researchers have focused more on morphological and electronic properties of pure and doped $\mathrm{CdO}$ as compare to other properties. Hence in this paper, it is proposed that thermal and absorbance of $\mathrm{CdO}$ could be tuned by suitable doping of divalent metal ion and therefore considered as the thrust topic of investigation. In this way, we have selected two divalent metal ions $(\mathrm{Cu}, \mathrm{Mn})$ as dopant and discussed the changes in thermal behavior and bandgap engineering. Besides, some interesting results are also highlighted owing to single $(\mathrm{Cu}$, $\mathrm{Mn})$ and double doping (Cu-Mn) in $\mathrm{CdO}$.

\section{Synthesis and Characterizations}

For sample preparation of $\mathrm{CdO}$ doped with different divalent metals (TM) ions, an easy and cheap co-precipitation method is chosen. The full explanation of synthesis method has been discussed in our previous publication (Bhukkal et al., 2020). After synthesis, all samples are calcined at similar $750^{\circ} \mathrm{C}$ (3h). To investigate the characteristic weight loss behavior of the prepared nanopowder, thermal analysis has been carried out from $25-900^{\circ} \mathrm{C}$ per $5^{\circ} \mathrm{C} / \mathrm{min}$ rate of heating. For this, Perkin Elmer STA 6000 thermal analyzer is being used to conduct the DSC and TGA measurements. Absorbance is analyzed in the UV-Vis range (200-900 nm) from Perkin Elmer Lambda 750 spectrophotometer.

\section{Results and Discussion}

\section{Thermal Analysis by DSC}

The physio-chemical nature of prepared samples is examined by Differential Scanning Colorimetric which generally establishes the thermal change either scanning mode (as a function of temperature) or isothermal mode (as a function of time). Fig. 1 shows the DSC traces for undoped and doped $\mathrm{CdO}$ samples which are obtained after centrifugation and drying the precipitates in oven.DSC curve emphasized prominent peaks at the temperatures: $45^{\circ} \mathrm{C}$, $195^{\circ} \mathrm{C}, 296^{\circ}$ and $730^{\circ} \mathrm{C}$ as exposed in Fig. 1(a). The initial decay at $50^{\circ} \mathrm{C}$ could be credited to the discharge of water available on the top layer of sample. Major endothermic peak at $195^{\circ} \mathrm{C}$ insured that sample absorbs heat to decompose the organic at the particular temperature with enthalpy $237.85 \mathrm{~J} / \mathrm{g}$ and also due to the change of hydroxide precursors into $\mathrm{CdO}$ (Bhukkal et 
al., 2020). However, few endothermic peaks are seemed at $296^{\circ} \mathrm{C}$ and $730^{\circ} \mathrm{C}$ which support the crystalline phase of cubic $\mathrm{CdO}$ nanocrystallite.
At last, beyond $750^{\circ} \mathrm{C}$, negligible mass loss is found that indicate the development of pure $\mathrm{CdO}$ at this temperature.
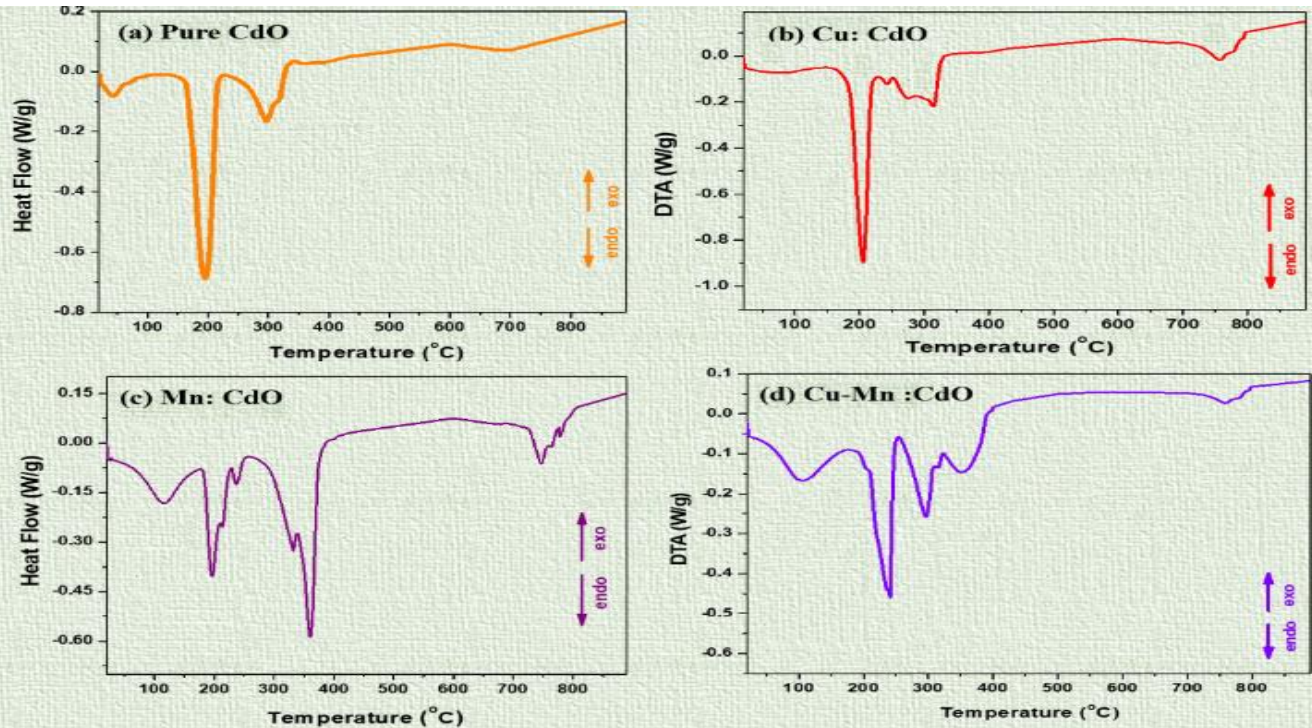

Figure 1: Differential Scanning Colorimetric curve for (a) Pure $\mathrm{CdO}$ (b) $\mathrm{Cu}$ doped $\mathrm{CdO}$

(c) $\mathrm{Mn}$ doped $\mathrm{CdO}$ (d) $\mathrm{Cu}-\mathrm{Mn}$ doped $\mathrm{CdO}$

DSC curve obtained for $\mathrm{Cu}$ doped $\mathrm{CdO}$ sample is depicted in Fig. 1(b). In this sample, major main peak is observed at $205^{\circ} \mathrm{C}$ that is endothermic and has enthalpy $=194.60 \mathrm{~J} / \mathrm{g}$. It is ascribed to burning of precursors specially citrates, organics and residual alkoxy groups (Bhukkal et al., 2020).Phase identification in cadmium oxides is confirmed by other two peaks noticed at $312^{\circ} \mathrm{C}$ and $738^{\circ} \mathrm{C}$. Moreover, two medium peaks are also found at temperature $240^{\circ} \mathrm{C}$ and $280^{\circ} \mathrm{C}$ with small enthalpy values as 3.45 and $7.01 \mathrm{~J} / \mathrm{g}$. All these peaks are emphasized the endothermic chemical reactions between precursors. Few impurities phases are also evolved on account of the peak at $312^{\circ} \mathrm{C}$ in DSC curve with $13.23 \mathrm{~J} / \mathrm{g}$ enthalpy. The significant peak in this sample is formed at $738^{\circ} \mathrm{C}$ and has enthalpy $9.4 \mathrm{~J} / \mathrm{g}$ owing to crystallization of the cubic $\mathrm{CdO}$.

For Mn doped CdO sample, DSC curve has been depicted in Fig. 1(c) which shows major endothermic peaks at $355^{\circ} \mathrm{C}$ along with three minor peaks at 110,190 and $750^{\circ} \mathrm{C}$. It is calculated from inbuilt software of DSC that major peak at $355^{\circ} \mathrm{C}$ that has enthalpy value $91.45 \mathrm{~J} / \mathrm{g}$. The particular peaks at $110^{\circ} \mathrm{C}$ corresponds to deletion of adsorbed water has 86 $\mathrm{J} / \mathrm{g}$ of enthalpy. Also, two endo-thermic peaks are noticed at $190^{\circ} \mathrm{C}$ with $35.75 \mathrm{~J} / \mathrm{g}$ enthalpy and at $740^{\circ} \mathrm{C}$ with $12 \mathrm{~J} / \mathrm{g}$ of enthalpy. Major endothermic peak has been occurred at $240^{\circ} \mathrm{C}$ similar to other samples [12].Peaks at 300 and 
$350^{\circ} \mathrm{C}$ are developed from the reaction of various chemicals while peak at $740^{\circ} \mathrm{C}$ is devoted to complete crystallization of cubic $\mathrm{CdO}$. For $\mathrm{Cu}-\mathrm{Mn}$ doped $\mathrm{CdO}$, major peak is evolved at $240^{\circ} \mathrm{C}$ with enthalpy $95.31 \mathrm{~J} / \mathrm{g}$ as shown in Fig. 1(d). The other relevant peaks exist at $100^{\circ} \mathrm{C}, 300^{\circ} \mathrm{C}$ and $750^{\circ} \mathrm{C}$ in DSC curve owing to enthalpies 473.54, 3.07 and $3.54 \mathrm{~J} / \mathrm{g}$, respectively (Bhukkal et al., 2020).

\section{Thermal Analysis (TGA)}

The potential of TGA to produce elemental quantitative data has led to its wide spread use in nanoscience and nanomaterials.For pure sample (a),TG- curve emphasized prominent weight losses of $15 \%, 35 \%, 12 \%$ and $3 \%$ which are in full support of the DSC curve of corresponding sample. The initial decay noticed from room temperature to $90^{\circ} \mathrm{C}$ which could be credited to the evaporation of water. The second stage of $35 \%$ weight loss occurred between $160-220^{\circ} \mathrm{C}$ which may be assigned to the phase transformation from precursor to cubic cadmium oxide and removal of acetates, carbonates etc (Singh et al.,2009). The third stage of weight loss $12 \%$ between $250-350^{\circ} \mathrm{C}$ predicted the improved crystallinity of the prepared nanocomposite. Further, a minimum weight loss of ) 3\%( observed in final stage between 700$750^{\circ} \mathrm{C}$, indicated complete appearance of cubic phase $\mathrm{CdO}$ nanocrystallites as well as removal of impurity phases. For $\mathrm{Cu}$ doped sample, entire weight loss $\sim 44 \%$ is detected in the entire $25^{\circ}$ $750^{\circ} \mathrm{C}$ range and after that no weight loss occurred for $\mathrm{Cu}$ doped $\mathrm{CdO}$ nanocrystallites. As depicted in Fig. 2(b), starting weight loss $\sim 11 \%$ is called $1^{\text {st }}$ step of TG analysis curve. The prominent peak in temperature range 186$218^{\circ} \mathrm{C}$ called as $2^{\text {nd }}$ step ( $25 \%$ weight loss) while negligible weight loss $(8 \%)$ is presented as $3^{\text {rd }}$ step in corresponding TGA curve (Bhukkal et al., 2020).

Further, the DSC graph of $\mathrm{Mn}$ doped $\mathrm{CdO}$ emphasized initial decay of 5\% noticed from $25-$ $110^{\circ} \mathrm{C}$ which is mainly due to the evaporation of water available on top facet of the sample. The next step of $7 \%$ loss of weight occurred between $180-200^{\circ} \mathrm{C}$ which may be attributed to the removal of acetates, carbonates etc (Singh et al., 2009). The next stage of weight loss $\sim 8 \%$ in the range $250-350^{\circ} \mathrm{C}$ predicted the improved crystallinity of the sample. Further, a small weight loss of ) 5\%( observed in final stage between $\quad 700-750^{\circ} \mathrm{C}$ signifies crystalline structure of cubic phase $\mathrm{CdO}$ nanocrystallites. 

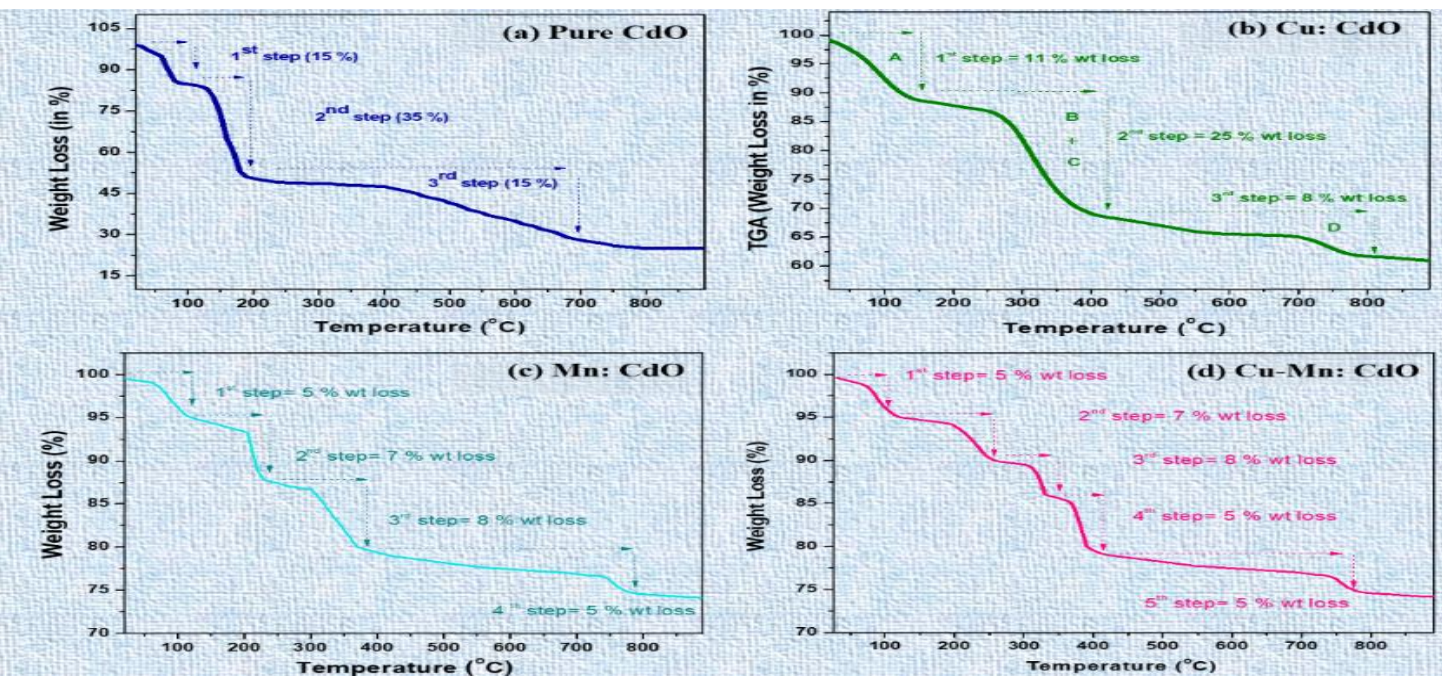

Figure 2: Thermo Gravimetric Analysis curve for (a) Pure $\mathrm{CdO}$ (b) $\mathrm{Cu}$ doped $\mathrm{CdO}$ (c) $\mathrm{Mn}$ doped $\mathrm{CdO}(\mathrm{d}) \mathrm{Cu}-\mathrm{Mn}$ doped $\mathrm{CdO}$.

For $\mathrm{Cu}-\mathrm{Mn}$ doped $\mathrm{CdO}$ sample, the TGA graph depicted the performance of entire weight loss $30 \%$ in the temperature range $25^{\circ} \mathrm{C}-800^{\circ} \mathrm{C}$ mainly due to the decomposition and modification of precursors in different phases. Every step is attributed to the chemical decomposition owing to distinct reaction of chemicals (Bhukkal et al., 2020). After $750^{\circ} \mathrm{C}$, there is no loss of weight; means crystallization is completed up to this temperature. The $3 \mathrm{rd}$ and 4th step with subsequent weight loss $\sim 8$ and 5\% has also been displayed in Fig. 2(d). The latter is ascribed to cubic crystalline phase of $\mathrm{CdO}$ that exist as the fundamental phase in doped samples. It is concluded that the weight loss observed in TGA graph of pure and doped $\mathrm{CdO}$ demonstrated multistep degradation processes.

\section{Uv-Vis Spectroscopy}

Fig. 3 (i) presents the disparity of incident photon wavelength and optical absorption in the UV-Vis-NIR region (200-800 $\mathrm{nm}$ ) for pure and doped $\mathrm{CdO}$. Each powder sample with a fixed amount was dissolved in ethanol solvent using ultrasonic machine and observed significant absorbance mainly in UV-region (Eskizeybek et al., 2011). A sharp and strong absorption peak near $214 \mathrm{~nm}$ is noticed in pure $\mathrm{CdO}$ with clear excitonic feature owing to the nanometer size of the prepared crystallites. In $\mathrm{Cu}$ doped $\mathrm{CdO}$ sample, one may observe a strong absorption peak positioned at $240 \mathrm{~nm}$ accompanied by a small lump in the 325-450 nmwavelength portion. Absorbance at $240 \mathrm{~nm}$ is due to excitonic features that is well matched with literature ( Bhukkal et al., 2019,2020). In this sample, broad hump recognized about $400 \mathrm{~nm}$ could be credited to the doping of divalent metal i.e. copper ions. 
(i) Absorption Spectra

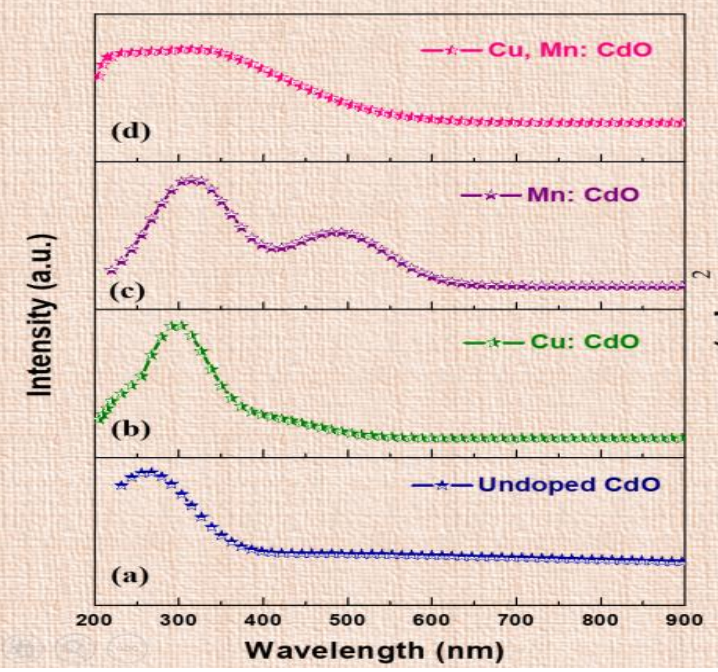

(ii) Tauc's Plot

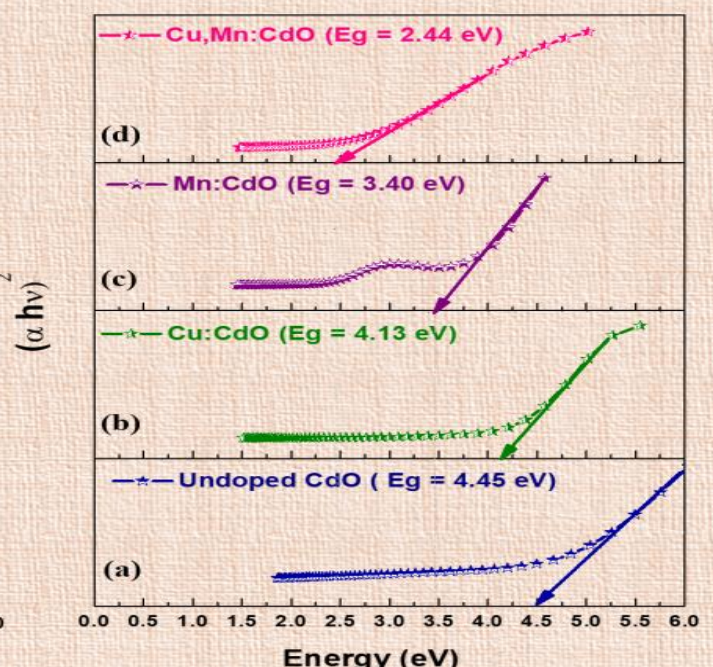

Figure 3(i): UV-Vis spectra and (ii) Band gap energy for (a) Pure $\mathrm{CdO}$ (b) $\mathrm{Cu}$ doped $\mathrm{CdO}$ (c) $\mathrm{Mn}$ doped $\mathrm{CdO}$ (d) $\mathrm{Cu}-\mathrm{Mn}$ doped $\mathrm{CdO}$.

The prepared $\mathrm{Cu}$ doped $\mathrm{CdO}$ nanopowder revealed in significant absorbance in the optical region, therefore may be utilized in solar cells (Thovhogi et al., 2016). For Mn doped CdO, the absorption edge is transferred towards the high energy as compare to pure $\mathrm{CdO}$ as shown in ' $\mathrm{c}$ ' part of Fig. 3(i). Here, two intense and broad optical absorption bands are obtained centered at $320 \mathrm{~nm}$ and $460 \mathrm{~nm}$. First peak is attributed to $\mathrm{CdO}$ while second peak may be originated from $\mathrm{Mn}^{2+}$ ions (Kumar et al., 2015). However, in $\mathrm{Cu}$ Mn doped CdO sample, a wide band is appeared in the region 220-380 $\mathrm{nm}$ while the band-edge approaches to the solar region (Bhukkal et al., 2020). In this investigation, the coefficient of absorbance is shifted a little towards higher wavelength range due to appropriate doping of divalent metal ions. Such a red shift happened in doped nanopowder stimulated the uses of such materials in modern optoelectronic devices.

\section{Bandgap Energy by Tauc's Plot}

The main difference in band gap of pure and doped sample is generated from nonstoichiometric composition and strongly depends on adopted synthesis rout (Rajput et al., 2017, Gupta et al., 2008). In general, band gap energy of the prepared samples is considered from the absorption spectra, wherever enrichment in the absorbance is observed possibly due to sharp band-to-band conversion. From absorption data,band gap energy $\left(E_{g}\right)$ gas been calculated for all prepared samples with the help of Tauc's relation as follows:

$$
(\alpha h v)^{1 / m}=\mathrm{A}\left(\mathrm{h} v-\mathrm{E}_{\mathrm{g}}\right)
$$

In this equation, $\alpha$ is known as absorption coefficient, ' $\mathrm{m}$ ' is considered as integer that 
depends on transition probability. Fig 3(b) exhibits the plot of $(\alpha h v)^{2}$ vs optical photon energy (hv) that is linear at advanced energy values $(>2.5)$ specifies optical direct transition (Bhukkal et al., 2020). When we put energy axis $\mathrm{x}=0$, one may notice that band gap energy $\mathrm{E}_{\mathrm{g}}$ can easily be inferred by extrapolating the straight region of the graph. The band gap energy $\left(E_{g}\right)$ of undoped sample of $\mathrm{CdO}=4.04$ $\mathrm{eV}$ while $\mathrm{Cu}$ doped sample has the band gap energy $\left(E_{g}\right)=3.86 \mathrm{eV}$. Further, for Mn doped sample, one can see the bangap energy $\left(E_{g}\right)=$ $3.07 \mathrm{eV}$ that is lower than the earlier calculated values of undoped and $\mathrm{Cu}$ doped sample. Moreover, the band gap energy $\left(\mathrm{E}_{\mathrm{g}}\right)$ of $\mathrm{Cu}-\mathrm{Mn}$ doped sample is attained as $2.14 \mathrm{eV}$ that is quite lesser than the literature bandgap of pure $\mathrm{CdO}$ (2.54 eV) (Purohit et al., 2017). This red shift is observed due to the occurrence of large energy levels allotted to few defect phases (Ziabari et al., 2012). Because due to doping of divalent metal ions, there is improvement of charge carriers in the conduction band that causes shift in the Fermi level leads to an increment of the bandgap energy of cubic $\mathrm{CdO}$. The alteration of optical band gap towards higher energy side observed in divalent metal ion doped $\mathrm{CdO}$ samples could be assigned to Burstein-Moss (BM) effect (Usharani et al., 2015). According to this effect, the deliberately doped ions reinforced the free charge carriers in the C.B. and modified the Fermi level in the forbidden gap. It is suggested that using optimum doping and most efficient co-doping, the band gap is significantly altered. Many super ficial faults and existence of impurity phase is also responsible for such observations. It is suggested that nanocrystallites size, defect states, imperfections at the grain boundaries and oxygen deficiency are the key aspects which significantly stimulus the optical absorption and hence bandgap.

\section{Conclusions}

In this paper, we have synthesized pure and $\mathrm{Cu}$, $\mathrm{Mn}, \mathrm{Cu}-\mathrm{Mn}$ doped $\mathrm{CdO}$ nanocrystallites are perfectly synthesized using the most viable coprecipitation technique. DSC curve analyzed that reaction between different precursors has been started approximately at $200^{\circ} \mathrm{C}$ and crystallization has been started at $350^{\circ} \mathrm{C}$. Further, negligible mass loss was detected after $750^{\circ} \mathrm{C}$ indicates the establishment of $\mathrm{CdO}$ nanopowder with no impurity phase even in doped samples. Multistep degradation of weight loss curve has been observed for all samples corresponding to endo/exothermic peaks of DSC graph. Strong optical absorbance is observed in UV-region (200-250 nm) attributed to excitonic band edge absorption. While, the visible portion mainly contributed by doped divalent metal ions i.e. $\mathrm{Cu}$, Mn.

\section{REFERENCES}

Bhukkal C, Ahlawat R (2019). Plate like $\mathrm{Cd}(\mathrm{OH})_{2}-\mathrm{CdO}$ nanocomposite: A study 
on surface morphology and band gap energy. AIP conference proceedings 2142: 140017.

Bhukkal C, Ahlawat R (2020). Cu2+$\mathrm{Mn} 2+-\mathrm{Co}-$ doped $\mathrm{CdO}$ nanocrystallites: comprehensive research on phase, morphology and optoelectronic properties. Research on Chemical Intermediates 46: 4211-4232.

Bhukkal C, Ahlawat R, Chauhan M (2020). Study of crystallographic modification in cadmium oxide $(\mathrm{CdO})$ nanocrystallites due to doped transition metal (TM) ions. Physica B: Condensed Matters 582: 411973.

Bhukkal C, Vats R, Goswami B, Rani N, Ahlawat R (2020). Synthesis of $\mathrm{Cu}$ doped $\mathrm{Cd}(\mathrm{OH}) 2-\mathrm{CdO}$ layered nanostructures and investigation of its different intermediate phases, optical and dcelectrical properties. Materials Today Communications 25: 101608.

Bhukkal C, Vats R, Goswami B, Rani N, R. Ahlawat R (2020). Synthesis of Cu doped $\mathrm{Cd}(\mathrm{OH}) 2-\mathrm{CdO}$ layered nanostructures and investigation of its different intermediate phases, optical and dcelectrical properties. Materials Today Communications 25: 101608.

Eskizeybek V, Demir O, Avei A, Chhowalla M (2011). Green synthesis of zinc oxide nanoparticles using flower extract of Nyctanthes arbor-tristis and their antifungal activity. J Nanopart Res 13: 4673-4680.

Gupta R K, Ghosh K, Patel R, Mishra S R, Kahol P K (2008). Highly conducting and transparent tin-doped $\mathrm{CdO}$ thin films for optoelectronic applications. Materials Letters 62: 4103- 4105.

Kumar S, Layek S, Yashpal M, Ojha A K (2015). Room temperature ferromagnetism in undoped and Mn doped CdO nanostructures. J Magnet and Mag Mat 393: 555-561.
Kumar S, Layek S, Yashpal M, Ojha A K (2015). Room temperature ferromagnetism in undoped and Mn doped $\mathrm{CdO}$ nanostructures. J Magnet and Mag Mat 393: 555-561.

Mohanraj K, Balasubramanian D (2017). Microstructural, Optical, Morphological, Luminescence and Electrical Properties of a $\mathrm{CdO}$ Nanocomposite Synthesized by a Chemical Route Assisted Microwave Irradiation Technique. Silicon DOI 10.1007/s12633-017-9579-0.

Purohit A, Chander S, Patel S L, Rangra K J, Dhaka M S (2017). Substrate dependent physical properties of evaporated $\mathrm{CdO}$ thin films for optoelectronic applications. Physics Letters A 318: 1910-1914.

Rajput J K, Pathak T K, Kumar V, Kumar M, Purohit L P (2017). Study of crystallographic modification in cadmium oxide $(\mathrm{CdO})$ nanocrystallites due to doped transition metal (TM) ions. Surfaces and Interfaces 6: 1117.

Rajput J K, Pathak Y K, Kumar V, Purohit L $P$ (2017). Tailoring and optimization of hybrid $\mathrm{ZnO}: \mathrm{TiO} 2: \mathrm{CdO}$ nanomaterials for advance oxidation process under visible light. Appl Surf Sci 40: 8-16.

Singh S C, Swarnkar R K, Gopal R (2009). Effect of oxygen injection on the size and compositional evolution of $\mathrm{ZnO} / \mathrm{Zn}(\mathrm{OH}) 2$ nanocomposite synthesized by pulsed laser ablation in distilled water. J Nanopart Res 11: 1831-1838.

Sivakumar S, Venkatesan A, Soundhirarajan P, Khatiwada C P (2015). Spectroscopic studies and antibacterial activities of pure and various levels of $\mathrm{Cu}$-doped $\mathrm{BaSO}_{4}$ nanoparticles. Spectrochim Acta A 15: 760-772. 
Thovhogi N, Park E, Manikandan E, Maaza M, Gurib-Fakim A (2016). Physical properties of $\mathrm{CdO}$ nanoparticles synthesized by green chemistry via Hibiscus Sabdariffa flower extract. Journal of Alloys and Compounds 655: 314-320.

Usharani K, Balu A R, Nagarethinam V S, Suganya M (2015). Study of crystallographic modification in cadmium oxide $(\mathrm{CdO})$ nanocrystallites due to doped transition metal (TM) ions. Progress in National Science: Material International 25: 251-257.

Ziabari A, Ghodsi F E, Kiriakidis G (2012). Influence of Al-doping on microstructure and optical properties of sol-gel derived $\mathrm{CdO}$ thin films Surf Coat 213: 15-20. 